\title{
Analisis Anatomi dan Trikoma Tanaman Obat Dandang Gendis Clinacanthus nutans (Burm. f.) Lindau
}

\author{
Elis Tambaru ${ }^{1}$, Samuel A. Paembonan ${ }^{2}$, Resti Ura'², Mustika Tuwo ${ }^{1}$ \\ ${ }^{I}$ Departemen Biologi, Fakultas Matematika dan Ilmu Pengetahuan Alam \\ Universitas Hasanuddin \\ ${ }^{2}$ Fakultas Kehutanan Universitas Hasanuddin \\ E-mail: eli.tambaru@yahoo.com
}

\begin{abstract}
Research on the analysis of the anatomy of the stomatal and trichomes of the medicinal plant Dandang Gendis Clinacanthus nutans (Burm.f.) Lindau in Makassar City. This study aims to determine the anatomical structure of the stomatal and trichomes of longitudinal cross-section of leaves that are used as herbal medicines. This research method was used to spread acetone to obtain stomatal prints on the leaf surface, the data were analyzed descriptively. The results of the analysis of the anatomy of the stomatal and trichomes of leaves of the medicinal plant Dandang Gendis Clinacanthus nutans (Burm.f.) Lindau was a diacytic type of stomatal, the spread of stomatal was only found on the surface of the abaxial leaf including the apple type. The number of abaxial stomatal was 160 stomatal $/ \mathrm{mm}^{2}$. The number of epidermal cells was 748 epidermis $/ \mathrm{mm}^{2}$ and abaxial 504 epidermis $/ \mathrm{mm}^{2}$, stomatal index $23.95 \%$, and stomatal size $159.26 \mu \mathrm{m}$. On the adaxial and abaxial surfaces of the leaves of Dandang Gendis Clinacanthus nutans (Burm.f.) Lindau, glandular and lithocyst trichomes were encountered.
\end{abstract}

Kata kunci: Stomatal, trichomes, medicinal plants

\section{PENDAHULUAN}

Tanaman Dandang Gendis Clinacanthus nutans (Burm.f.) Lindau merupakan salah satu jenis tanaman herbal, di Indonesia masyarakat dapat memanfaatkan jenis tanaman ini untuk pengobatan tradisional, sebagai tindakan pencegahan maupun pengobatan terhadap berbagai jenis penyakit. Pada permukaan daun tanaman terdapat stomata yang merupakan derivat epidermis. Stomata dalam fisiologi tumbuhan berperan sangat penting pada proses fotosintesis, transpirasi dan respirasi (Tambaru, 2015; Larcher, 1995). Stomata merupakan tempat pertukaran gas karbon dioksida $\left(\mathrm{CO}_{2}\right)$ dari luar ke dalam jaringan daun dan oksigen $\left(\mathrm{O}_{2}\right)$ dari jaringan tanaman ke atmosfir (Kumekawa et al. 2013). Selain stomata pada permukaan daun juga terdapat trikoma dan lithocyst merupakan derivat dari epidermis yang berfungsi melindungi tumbuhan dari kerusakan mekanis pada jaringan daun (Mulyani, 2006; Pandey dan Chadha, 1996).

Hasil metabolisme sekunder yang dihasilkan dari proses fotosintesis tanaman berupa senyawa kimia seperti: alkaloid, terpenoid dan fenolik (Salisbury dan Ross, 1992). Hasil metabolisme sekunder bermanfaat sebagai obat, zat pewarna, racun dan pengharum makanan (Kunsorn et al. 2013; Pandey dan Chadha, 1996). Penggunaan obat herbal sebagai salah satu alternatif pengobatan terhadap tingginya 
harga obat sintesis. Hasil penelitian dari Haetrakul et al. 2017; Nurlita et al. 2008, ekstrak daun Dandang Gendis mengandung senyawa terpenoid, flavonoid, flavon sulfur, minyak atsiri dan saponin. Senyawa kimia dalam daun Dandang Gendis bermanfaat sebagai antikanker, antioksidan, antidiabetes. Anti herpes (Kunsorn et al. 2013), digigit ular dan obat demam (Aslam et al. 2015).

Berdasarkan permasalahan di atas, maka dilakukan penelitian mengenaianalisis anatomi stomata dan trikoma tanaman obat Dandang Gendis Clinacanthus nutans (Burm.f.) Lindau di Kota Makassar.

\section{METODE PENELITIAN}

\section{Lokasi Penelitian}

Penelitian dilakukan pada bulan Februari 2019, pengambilan sampel tanaman di lokasi Bumi Tamalanrea Permai (BTP) Makassar. Analisis sampel penelitian dilakukan di Laboratorium Botani Departemen Biologi FMIPA Universitas Hasasanuddin Makassar.

\section{Prosedur Kerja}

Analisis karakteristik anatomi stomata dan trikoma, morfologi daun (Mulyani, 2006; Pandey dan Chadha, 1996; Tjitrosoepomo,1990). Daun penelitian diolesi aseton dan dibiarkan selama 3 menit, hasil cetakan stomata penampang membujur, selanjutnya dilekatkan di atas objek glass dan diamati pada mikroskop binokuler, sampel stomata yang diperoleh kemudian difoto pada mikroskop Bino \& Photo, parameter untuk jumlah stomata, sel epidermis dan trikoma diamati di mikroskop perbesaran 200x. Pengamatan ukuraran panjang dan lebar stomata perbesaran 400x. Karakterisasi tipe stomata (Hidayat, 2009; Sunarti et al. 2008; dan Nugroho et al. 2006). Perhitungan Indeks Stomata (IS) berdasarkan rumus (Damayanti, 2007) adalah sebagai berikut:

$$
\mathrm{IS}=\frac{\mathrm{S} / \mathrm{L}}{(\mathrm{S}+\mathrm{E}) / \mathrm{L}} \times 100 \%
$$

Keterangan: $\mathrm{S}$ : jumlah stomata $\quad \mathrm{E}$ : jumlah epidermis $\quad$ L : satuan luas daun

Pengkuran stomata dapat diukur dengan rumus Franco (Abdulrahaman et al. 2013 dalam Tambaru, 2018;) adalah sebagai berikut: SS= LxBxK

Dimana: Stomata Size (SS), L: Panjang B: lebar K: konstanta Franco’s $(0,79)$.

\section{Analisis Data}

Data analisis karakterisasi anatomi stomata dan trikoma daun tanaman obat Dandang Gendis Clinacanthus nutans (Burm.f.) Lindau dianalisis secara deskriptif.

\section{HASIL DAN PEMBAHASAN}

Hasil penelitian mengenai analisis anatomi stomata dan trikoma daun tanaman obat Dandang Gendis Clinacanthus nutans (Burm.f.) Lindau disajikan pada Gambar 1 dan Tabel 1-2. 


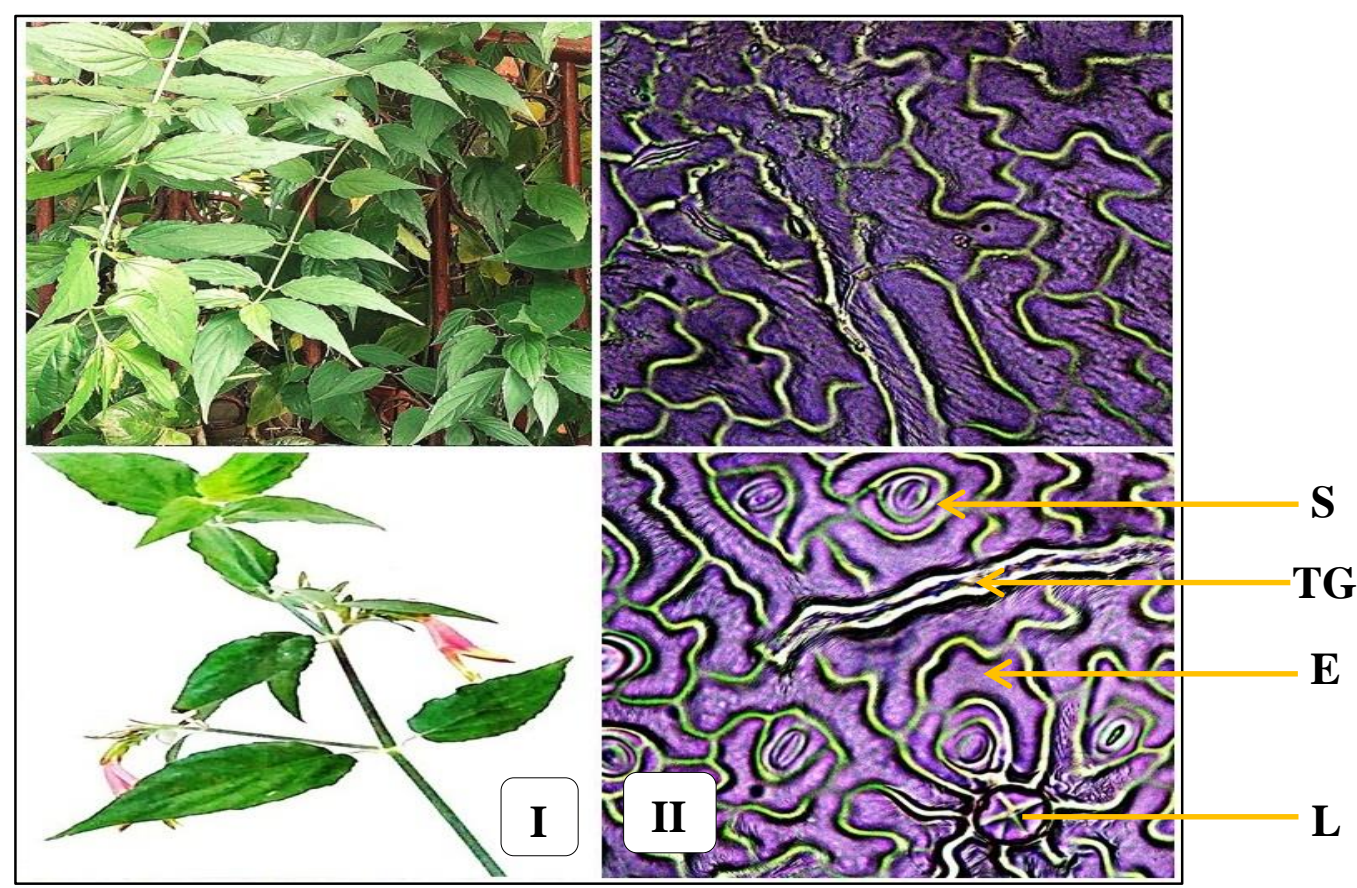

Gambar 1. Morfologi Tanaman (I), Anatomi Stomata dan Trikoma Daun Tanaman Dandang Gendis (II); Stomata (S), Epidermis (E), Trikoma Grandular (TG), Lithocyst (L) Penampang Membujur dengan Perbesaran 400x.

Tabel 1. Karakteristik Anatomi Stomata Penampang Membujur dan Trikoma Tanaman Dandang Gendis

\begin{tabular}{lcc}
\hline \multicolumn{1}{c}{ Karakteristik } & & \multicolumn{1}{c}{ Dandang Gendis } \\
& & Clinacanthus \\
& & Diatans (Burm.tik \\
Tipe Somata & Apel \\
Tipe Penyebaran Somata Pada Permukaan Daun & 748 \\
Jumlah Epidermis $\left(\mathrm{mm}^{2}\right)$ & Adaxial & 508 \\
& Abaxial & 0 \\
Jumlah Somata $\left(\mathrm{mm}^{2}\right)$ & Adaxial & 160 \\
& Abaxial & 0 \\
Panjang Stomata $(\mu \mathrm{m})$ & Adaxial & 16,8 \\
& Abaxial & 0 \\
Lebar Stomata $(\mu \mathrm{m})$ & Adaxial & 12,0 \\
& Abaxial & 0 \\
Ukuran Stomata $(\mu \mathrm{m})$ & Adaxial & 159,26 \\
& Abaxial & 0 \\
Indeks Stomata $(\%)$ & Adaxial & 23,95 \\
& Abaxial & Berlekuk dangkal \\
Dinding Sel Epidermis & Adaxial & Berlekuk dangkal \\
& Abaxial & Tidak Beraturan \\
Tipe Sel Epidermis & Adaxial & Tidak Beraturan \\
& Abaxial & 44 \\
Jumlah Trikoma Glandular & Adaxial & 48 \\
$(\mu \mathrm{m})$ & Abaxial & 16 \\
Jumlah Lithocyst $(\mu \mathrm{m})$ & Adaxial & 20 \\
\hline
\end{tabular}


Tabel 2. Kandungan Senyawa Kimia dan Manfaat Tanaman Dandang Gendis

\begin{tabular}{|c|c|c|c|c|}
\hline Tanaman & $\begin{array}{c}\text { Kandungan } \\
\text { Senyawa Kimia }\end{array}$ & Manfaat Tanaman & $\begin{array}{c}\text { Bagian } \\
\text { Tanaman }\end{array}$ & Penelitian \\
\hline $\begin{array}{l}\text { Dandang } \\
\text { Gendis }\end{array}$ & $\begin{array}{l}\text { Flavanoid, tanin, } \\
\text { alkaloid, saponin, } \\
\text { dan steroid }\end{array}$ & Antivirus & Daun & $\begin{array}{l}\text { Haetrakul et al. } \\
2017\end{array}$ \\
\hline $\begin{array}{l}\text { Dandang } \\
\text { Gendis }\end{array}$ & $\begin{array}{l}\text { Flavanoid, terpenoid } \\
\text { dan flavonsulfur }\end{array}$ & $\begin{array}{l}\text { Antikanker, } \\
\text { antidiabetes, } \\
\text { antioksidan, dan } \\
\text { antianalgetik }\end{array}$ & Daun & $\begin{array}{l}\text { Yahaya et al. 2015; } \\
\text { Jamil et al. } 2018\end{array}$ \\
\hline $\begin{array}{l}\text { Dandang } \\
\text { Gendis }\end{array}$ & $\begin{array}{l}\text { Alkaloida, saponin, } \\
\text { tanin, dan minyak } \\
\text { atsiri }\end{array}$ & $\begin{array}{l}\text { Menurunkan kadar } \\
\text { gula, antikanker, dan } \\
\text { antitumor }\end{array}$ & Daun & $\begin{array}{l}\text { Nurulita, 2008; } \\
\text { Zulkipli et al. } 2017\end{array}$ \\
\hline $\begin{array}{l}\text { Dandang } \\
\text { Gendis }\end{array}$ & $\begin{array}{l}\text { Flavanoid, } \\
\text { glycosides, } \\
\text { glycoglycerolipids, } \\
\text { cerebrosides dan } \\
\text { acylmonogalatosylgl } \\
\text { cerol }\end{array}$ & $\begin{array}{l}\text { Antiinflamasi, } \\
\text { antivirus, antioksidan, } \\
\text { antidiabetik, Ruam } \\
\text { kulit, digigit serangga } \\
\text { dan kalajengking }\end{array}$ & Daun & $\begin{array}{l}\text { Alam et al. } 2016 \\
\text { Nugraheni et al. } \\
2017\end{array}$ \\
\hline
\end{tabular}

Tanaman Dandang Gendis Clinacanthus nutans (Burm.f.) Lindau berhabitus semak-perdu (shrub), sistem perakaran tunggang, batang bulat bewarna hijau. Daun tunggal berhadapan, percabangan muncul dari ketiak daun. Bangun daun bulat memanjang (elliptico-oblongus), ujung daun meruncing, tepi daun berombak (repens), pertulangan daun menyirip, pangkal daun membulat, daging daun seperti kertas, warna daun hijau. Panjang daun 9,2-11,8 cm, lebar daun 4,4-5,3 $\mathrm{cm}$ dan panjang tangkai daun 12,9 cm. Bunga majemuk cymosa muncul dari ketiak daun/ujung batang. Mahkota bunga berbentuk tabung dengaan ukuran 2-3 cm, berwarna merah muda, buah tanaman ini berbentuk kotak bulat memanjang, berisi \pm 4 biji/buah. Berkembang biak dengan biji dan stek batang. Tanaman Dandang Gendis Clinacanthus nutans (Burm.f.) Lindau termasuk anggota Familia Acanthaceae.

Hasil penelitian analisis anatomi stomata dan trikoma tanaman Dandang Gendis Clinacanthus nutans (Burm.f.) Lindau, berdasarkan susunan sel-sel tetangga yang ada di samping sel penutup , stomata tersebut dikelilingi oleh dua sel tetangga. Dinding sel bersama dari kedua sel tetangga tegak lurus terhadap sumbu panjang sel penutup serta celah disebut tipe diasitik (Mulyani, 2006; Pandey dan Chadha, 1996). Stomata hanya dijumpai pada permukaan bawah daun abaxial, sedang permukaan atas daun adaxial tidak ada stomata (Gambar 1). Penyebaran stomata hanya pada permukaan bawah daun disebut tipe apel (Pandey dan Chadha, 1996). Hasil penelitian pada Tabel 1, jumlah stomata abaxial sebanyak 160 stomata $/ \mathrm{mm}^{2}$, jumlah epidermis adaxial 748 epidermis $/ \mathrm{mm}^{2}$, jumlah epidermis abaxial 508 epidermis $/ \mathrm{mm}^{2}$. Panjang stomata rata-rata $16,8 \mu \mathrm{m}$, lebar stomata rata-rata $12,0 \mu \mathrm{m}$, indeks stomata rata-rata $23,59 \%$, dan ukuran stomata rata-rata 159,26 $\mu \mathrm{m}$. Jenis tanaman Dandang Gendis jumlah stomatanya sangat sedikit karena jumlanya kurang dari 300 stomata/mm ${ }^{2}$, begitu pula dengan panjang stomata di bawah $20 \mu \mathrm{m}$, sehingga kurang panjang (Hidayat, 2009).

Hasil penelitian menunjukkan bahwa ukuran stomata daun berpengaruh terhadap jumlah stomata serta penyebaran stomata daun. Hasil fotosintesis sangat dipengaruhi oleh jumlah stomata, ukuran stomata, panjang stomata, lebar stomata, dan indeks stomata pada permukaan daun (Palit, 2008). 
Hasil fosintesis berupa metabolisme sekunder yang berfungsi sebagai obat herbal antara lain: fenolik, terpenoid dan alkaloid (Salisbury dan Ross, 1992).

Hasil penelitian pada Gambar 1 dan Tabel 1, daun Dandang Gendis pada permukaan daun adaxial dan abaxial dijumpai adanya trikoma glandular, pada bagian adaxial 44 trikoma glandular $/ \mathrm{mm}^{2}$, abaxial 48 trikoma glandular/mm² dan lithocyst bagian adaxial 16 lithocyst $/ \mathrm{mm}^{2}$ dan abaxial 20 lithocyst $/ \mathrm{mm}^{2}$. Trikoma glandular atau rambut kelenjar berperan dalam sekresi berbagai senyawa seperti garam, madu, terpen, dan polisakarida. Lithocyst sel yang dindingnya mengalami penebalan secara sentripetal, penebalan tersebut mengandung pektin, sellulosa dan Ca karbonat, umumnya dijumpai pada tanaman Familia Acanthaceae dan Moraceae (Kunsorn et al. 2013; Mulyani, 2006).

Berbagai hasil penelitian dari daun tanaman Dandang Gendis berfungsi sebagai obat herbal untuk mengatasi berbagai macam penyakit dan kandungan senyawa kimianya ditunjukkan pada Tabel 2. Kandungan senyawa kimia pada daun yaitu: flavonoid, tanin, alkaloid, saponin, berfungsi sebagai obat herbal antivirus (Nugrahaeni et al. 2017), ruam kulit, digigit serangga, kalajengking (Alam et al. 2016) dan antibakteri (Zulkipli et al. 2017). Penelitian Yahaya et al. 2015; Sinaga, 2011; Jamil et al. 2018) daun Dandang Gendis mengandung senyawa terpenoid, flavonoid, flavon sulfur, berfungsi sebagai obat herbal mengobati luka, antikanker, antidiabetes. Hasil penelitian dari Zulkipli et al. 2017; Nurulita et al. 2008, daun Dandang Gendis mengandung senyawa alkaloida, saponin, tanin, dan minyak atsiri berfungsi menurunkan kadar gula, antikanker dan antitumor. Hasil penelitian Raya et al. 2015, bahwa tanaman Dandang Gendis pada daun muda mengandung lebih banyak senyawa fitokimia dari daun yang tua. Perbanyakan tanaman Dandang Gendis lebih cepat pertumbuhannya dengan stek batang.

\section{KESIMPULAN}

Hasil penelitian analisis anatomi stomata dan trikoma daun tanaman obat Dandang Gendis Clinacanthus nutans (Burm.f.) Lindau adalah tipe stomata diasitik, penyebaran stomata hanya terdapat pada permukaan daun abaxial termasuk tipe apel. Jumlah stomata abaxial 160 stomata/ $\mathrm{mm}^{2}$. Jumlah sel epidermis adaxial 748 epidermis $/ \mathrm{mm}^{2}$ dan abaxial 504 epidermis $/ \mathrm{mm}^{2}$, indeks stomata 23,95\%, dan ukuran stomata 159,26 $\mu \mathrm{m}$. Pada permukaan adaxial dan abaxial daun Dandang Gendis Clinacanthus nutans (Burm.f.) Lindau dijumpai trikoma glandular dan lithocyst.

\section{DAFTAR PUSTAKA}

Alam A., S. Ferdosh, K. Ghafoor, A. Hakim, A. S. Juraimi, A. Khatib, Z. I. Sarker. 2016. Clinacanthus nutans: A Review of the Medicinal Uses, Pharmacology and Phytochemistry. Asian Pacific Journal of Tropical Medicine 9(4): 402-409.

Aslam M. S., M. S. Ahmad and A. S. Mamat. 2015. A Review on Phytochemical Constituents and Pharmacological Activities of Clinacanthus Nutans. International Journal of Pharmacy and Pharmaceutical Sciences 7(2): 30-33.

Damayanti, F., 2007. Analisis Kromosom dan Anatomi Stomata pada Beberapa Plasma Nutfah Pisang (Musa sp.) Asal Kalimantan Timur. Bioscientiae 4(2): 53-61.

Haetrakul T., S. G. Dunbar and N. Chansue. 2018. Antiviral Activities of Clinacanthus nutans (Burm.f.) Lindau Extract Against Cyprinid Herpesvirus 3 in Koi (Cyprinus carpio koi). Journal Fish Diseases 41(4): 581-587. 
Hidayat, S.R., 2009. Analisis Karakteristik Stomata, Kadar Klorofil dan Kandungan Logam Berat pada Daun Pohon Pelindung Jalan Kawasan Lumpur Porong Sidoarjo. Fakultas Sains dan Teknologi Universitas Islam Malang, hal. 35-59.

Jamil, S., A. W. Kurdi, M.Y. Goh, M.Ebrahimi, N. Mohtarrudin, and Z.B. Hashim, 2018. Sub-acute Oral Toxicity Profiling of the Methanolic Leaf Extract of Clinachanthus nutans in Male and Female ICR Mice. International Journal of Pharmaceutical Sciences 10(12).

Kumekawa, Y., H. Miyaka, K. Ohga, H. Hayakawa, J. Yokoyama, K. Ito, S. Tebaya, R. Arakawa, and

T. Fukuda. 2013. Comparative Analyses of Stomatal Size and Density Among Ecotypes of Aster hispidus (Asteraceae). American Journal of Plant Sciences 4: 524-527.

Kunsorn P., N. Ruangrungsi, V. Lipipun, A. Khanboon, K. Rungsihirunrat. 2013. The Identities and Anti-herpes Simplex Virus Activity of Clinacanthus nutans and Clinacanthus siamensis. Asian Pacific Journal of Tropical Biomedicine 3(4): 284-290.

Larcher, W., 1995. Physiological Plant Ecology Ecophysiology and Stress Physiology of Functional Groups. Third Edition. Springer-Verlag Berlin Heidelberg. Printed in Berlin, 506 pp.

Mulyani, E.S., 2006. Anatomi Tumbuhan. Penerbit Kanisius Yogyakarta, hal.132-157.

Nugraheni B., E. A. Narasukma, I. M. Cahyania, C. Retnaningsih, V. K. Ananingsih. 2017. Antioxidant Activity Test and Determination of Ec50 Extract and Fraction of Dandang Gendis Leaves (Clinacanthus nutans) By DPPH Method (1,1-Diphenyl-2-Picrylhydrazyl) in Vitro. Proceeding of The $2^{\text {nd }}$ UMP-PIC \& $8^{\text {th }} I S C C$ 13-14 October 2017, Universitas Muhammadiyah Purwokerto, pp. 98-103.

Nugroho, L.H., Purnomo dan I. Sumardi. 2006. Struktur \& Perkembangan Tumbuhan. Penerbit Penebar Swadaya. Jakarta, hal. 84-119.

Nurulita Y., H. Dhanutirto, A. A. Soemardji. 2008. Penapisan Aktivitas dan Senyawa Antidiabetes Ekstrak Air Daun Dandang Gendis (Clinacanthus nutans). Jurnal Natur Indonesia 10(2): 98103.

Palit, J.J., 2008. Teknik Perhitungan Jumlah Stomata Beberapa Kultivar Kelapa. Buletin Teknik Pertanian 13(1): 1-23.

Pandey, S.N. and A. Chadha. 1996. A Texbook of Botany Plant Anatomy and Economic Botany. Volume III. Vikas Publishing House PVT LTD New Delhi, pp. 96-103.

Raya K. B., S. H. Ahmad, S. F. Farhana, M. Mohammad, N. E. Tajidin, and A. Parvez. 2015. Changes In Phytochemical Contents In Different Parts Of Clinacanthus nutans (Burm. F.) Lindau Due To Storage Duration. Bragantia Campinas 74(4): 445-452.

Salisbury, F.B. and C.W. Ross. 1992. Plant Physiology. Wardsworth Publishing Company Belmont California, $682 \mathrm{pp}$.

Sinaga, K. R., 2011. Pengujian Ekstrak Etanol Daun Dandang Gendis (Clinacanthus nutans (Burm. f.) Lindau) Terhadap efek Hipoglikemik. Prosiding Seminar Nasional Biologi: Meningkatkan Peran Biologi dalam Mewujudkan National Archievement with Global Reach, hal. 251-261.

Sunarti, S., Rugayah, E.F. Tihurun. 2008. Studi Anatomi Daun Jenis-jenis Averrhoa di Indonesia untuk Mempertegas Status Taksonominya. Berita Biologi 9(3): 253-257. 
Tambaru, E., R. Ura' dan M.Tuwo. 2018. Karakterisasi Stomata Tanaman Obat Andredera cordifolia (Ten.) Steenis dan Gratophyllum pictum (L.) Griff. Jurnal Ilmu Alam dan Lingkungan 9(17): 4247.

Tambaru, E., 2015. Identifikasi Karakteristik Morfologi dan Anatomi Stomata Flacourtia inermis Roxb. Di Kawasan Kampus Unhas Tamalanrea Makassar. Jurnal Ilmu Alam dan Lingkunga 6(11): $37-$ 41.

Tjitrosoepomo, G., 1990. Morfologi Tumbuhan. Gadjah Mada Universiy Press. Yogyakarta, 256 hal.

Yahaya R., G. K. Dash, M. S. Abdullah and A. Mathews. 2015. Clinacanthus nutans (burm. F.) Lindau: An Useful Medicinal Plant of South-East Asia. International Journal of Pharmacognosy and Phytochemical Research 7(6): 1244-1250.

Zulkipli I. N., R. Rajabalaya, A. Idris, N. A.Sulaiman and S. R. David. 2017. Clinacanthus nutans: A Review on Ethnomedicinal Uses, Chemical Constituents and Pharmacological Properties. Pharmaceutical Biology 55(1): 1093-1113. 